\title{
Association of polymorphisms rs1800012 in COL1A1 with sports-related tendon and ligament injuries: a meta-analysis
}

\author{
Chunguang Wang ${ }^{1}$, Hao Li ${ }^{1}$, Kang Chen ${ }^{1}$, Bing $\mathrm{Wu}^{1}$ and Haifeng Liu ${ }^{1}$ \\ ${ }^{1}$ Department of Sports Medical, The First Affiliated Hospital of Shenzhen University, Shenzhen Second People's Hospital, \\ Futian District, Shenzhen, Guangdong, China \\ Correspondence to: Haifeng Liv, email: haifengliv123@gmail.com \\ Keywords: COL1A1 polymorphism, rs1800012, sports injury, tendon and ligament injury, ACL injury \\ Received: July 14, 2016 \\ Accepted: January 26, 2017 \\ Published: February 11, 2017 \\ Copyright: Wang et al. This is an open-access article distributed under the terms of the Creative Commons Attribution License (CC-BY), \\ which permits unrestricted use, distribution, and reproduction in any medium, provided the original author and source are credited.
}

\section{ABSTRACT}

It has been reported that the single nucleotide polymorphism (SNP) rs1800012 in COL1A1 might be associated with the susceptibility to sportsrelated tendon and ligament injuries such as ACL injuries, Achilles tendon injuries, shoulder dislocations and tennis elbow. But the data from different studies have been conflicting. Here we attempted to systematically summarize and clarify the association between the SNP and sports-related tendon and ligament injuries risk. Six eligible studies including 933 cases and 1,381 controls were acquired from PubMed, Web Of Science and Cochrane library databases. Significant association was identified in homozygote model (TT versus GG: $O R=0.17,95 \% C I 0.08-0.35, P_{H}=0.00$ ) and recessive model (TT versus GT/GG: $\left.O R=0.21,95 \% C I 0.10-0.44, P_{H}=0.00\right)$. Our results indicated that COL1A1 rs1800012 polymorphism may be associated with the reduced risk of sports-related tendon or ligament injuries, especially in ACL injuries, and that rare TT may played as a protective role.

\section{INTRODUCTION}

With the improved quality of life, increasingly sports demands were raised, and growing individuals are suffering from sports injuries, which is estimated of a 15.47 per 1,000 incidence in NCAA athletes [1]. Sports injuries occurred all around us while tendon and ligament injuries constitute the most. [2]

Tendons and ligaments are collagenous structures which is made up of type I collagen fibrils. [3, 4] And COL1A1 encoding the Type I collagen, is indicative of a relationship between them. Actually, there do be plenty of literatures that reporting the association of COL1A1 with tendon and ligament injuries susceptibility. Single nucleotide polymorphisms (SNPs), occurring in the COL1A1 gene region, may alter the COL1A1 expression and affect the property of COL1A1 and subsequently lead to the susceptibility to injury. Among various polymorphisms within the COL1A1 gene, the most frequently studied polymorphism has been the $+1245 \mathrm{G} / \mathrm{T}$ polymorphism (rs1800012, Sp1), it is a $\mathrm{G}$ to $\mathrm{T}$ polymorphism lying within the first intron of COL1A1 affecting a binding site for the transcription factor Sp1. $[5,6]$

A multiple of diseases can have a genetic disorder, some are the Mendelian inherited conditions while the others are non-Mendelian inheritance spectrum such as tendon and ligament injuries, which are results from multifactorial issues and the severity of the conditions are determined by the complex gene-gene and geneenvironment interactions [7]. Studies focus on identifying the association of genetic mutations with tendon and ligament injuries are of important significance and could help to predict injury risk for specific individuals or guide the clinical management of 'high-risk' individuals $[8$, 9]. Although several articles have been reported on the association between rs 1800012 and the risk of tendon and ligament injuries in diverse population, the results were mixed and inconclusive. Up to now, there is no meta-analysis investigating the association between them. Therefore, we performed a meta-analysis to evaluate the association between rs 1800012 and tendon and ligament injuries risk. 
Table 1: Characteristics of studies included in the meta-analysis of COL1A1 rs1800012 G>T and sports injuries risk

\begin{tabular}{|c|c|c|c|c|c|c|c|c|c|c|c|c|}
\hline \multirow[t]{2}{*}{ Study ID } & \multirow[t]{2}{*}{ Year } & \multirow[t]{2}{*}{ Country } & \multirow[t]{2}{*}{ Ethnicity } & \multirow[t]{2}{*}{ Diagnosis } & \multicolumn{3}{|c|}{ Case } & \multicolumn{3}{|c|}{ Control } & \multirow[t]{2}{*}{\begin{tabular}{|c|} 
P for \\
HWE \\
\end{tabular}} & \multirow[t]{2}{*}{ Quality } \\
\hline & & & & & GG & GT & TT & GG & GT & TT & & \\
\hline Khoschnau et al. & 2008 & Sweden & Caucasian & $\begin{array}{l}\text { All } \\
\text { Cruciate ligament } \\
\text { ruptures } \\
\text { Shoulder dislocations }\end{array}$ & $\begin{array}{l}257 \\
162 \\
95\end{array}$ & $\begin{array}{l}99^{*} \\
70 \\
30\end{array}$ & $\begin{array}{l}2 \\
1 \\
1\end{array}$ & 230 & 83 & 12 & 0.20 & $* * * * *$ \\
\hline Posthumus et al. & $2009 a$ & South Africa & Caucasian & ACL injuries & 80 & 37 & 0 & 91 & 33 & 6 & 0.20 & $* * * * *$ \\
\hline Posthumus et al. & $2009 b$ & South Africa & Caucasian & $\begin{array}{ll}\begin{array}{l}\text { Achilles } \\
\text { injuries }\end{array} & \text { tendon } \\
\end{array}$ & 91 & 33 & 2 & 89 & 31 & 6 & 0.14 & $* * * * *$ \\
\hline Ficek et al. & 2013 & Poland & Caucasian & ACL injuries & 65 & 26 & 0 & 96 & 41 & 6 & 0.55 & $* * * * * *$ \\
\hline $\begin{array}{l}\text { Stepien-Slodkowska et al. } \\
\text { Erduran et al. }\end{array}$ & $\begin{array}{l}2013 \\
2014\end{array}$ & $\begin{array}{l}\text { Poland } \\
\text { Turkey }\end{array}$ & $\begin{array}{l}\text { Caucasian } \\
\text { Caucasian }\end{array}$ & $\begin{array}{l}\text { ACL injuries } \\
\text { Tennis elbow }\end{array}$ & $\begin{array}{l}90 \\
69\end{array}$ & $\begin{array}{l}46 \\
32\end{array}$ & $\begin{array}{l}2 \\
2\end{array}$ & $\begin{array}{l}139 \\
61\end{array}$ & $\begin{array}{l}39 \\
35\end{array}$ & $\begin{array}{l}5 \\
7\end{array}$ & $\begin{array}{l}0.27 \\
0.52\end{array}$ & $\begin{array}{l}* * * * * * \\
* * * * * *\end{array}$ \\
\hline
\end{tabular}

*1 patient had both diagnoses

\#chronic Achilles tendinopathy and ruptures of the Achilles tendon

Table 2: Summary of polled ORs in the meta-analysis

\begin{tabular}{|c|c|c|c|c|c|c|c|c|c|c|c|}
\hline rs1800012 & $\mathbf{N}$ & OR & $\mathbf{P}_{\mathrm{H}}$ & OR & $\mathbf{P}_{\mathrm{H}}$ & OR & $\mathbf{P}_{\mathrm{H}}$ & OR & $\mathbf{P}_{\mathrm{H}}$ & OR & $\mathbf{P}_{\mathrm{H}}$ \\
\hline & & $T / G$ & & GT/GG & & TT/GG & & TT+GT/GG & & TT/GT+GG & \\
\hline Overall & 6 & $0.89(0.75-1.05)$ & 0.17 & $1.13(0.93-1.38)$ & 0.23 & $0.17(0.08-0.35)$ & 0.00 & $1.00(0.83-1.22)$ & 0.97 & $0.21(0.10-0.44)$ & 0.00 \\
\hline \multicolumn{12}{|l|}{ Diagnosis } \\
\hline ACL injuries & 3 & $1.02(0.78-1.33)$ & 0.90 & $1.34(0.98-1.83)$ & 0.07 & $0.23(0.07-0.79)$ & 0.02 & $1.19(0.87-1.61)$ & 0.27 & $0.21(0.06-0.73)$ & 0.01 \\
\hline CL injuries & 1 & $0.93(0.67-1.28)$ & 0.65 & $1.20(0.82-1.74)$ & 0.35 & $0.12(0.02-0.92)$ & 0.04 & $1.06(0.73-1.53)$ & 0.75 & $0.11(0.01-0.87)$ & 0.04 \\
\hline Achilles tendon & 1 & $0.84(0.52-1.35)$ & 0.46 & $1.04(0.59-1.84)$ & 0.89 & $0.33(0.06-1.66)$ & 0.18 & $0.93(0.54-1.60)$ & 0.78 & $0.32(0.06-1.63)$ & 0.17 \\
\hline Shoulder & 1 & $0.74(0.48-1.13)$ & 0.16 & $0.88(0.54-1.42)$ & 0.59 & $0.20(0.03-1.57)$ & 0.13 & $0.79(0.49-1.26)$ & 0.33 & $0.21(0.03-1.62)$ & 0.13 \\
\hline Tennis elbow & 1 & $0.68(0.42-1.10)$ & 0.11 & $0.81(0.45-1.46)$ & 0.48 & $0.25(0.05-1.26)$ & 0.09 & $0.72(0.41-1.26)$ & 0.25 & $0.27(0.06-1.34)$ & 0.11 \\
\hline
\end{tabular}

\section{RESULTS}

\section{Characteristics of studies}

A total of 1200 studies were acquired from PubMed, Web Of Science and Cochrane library databases (PubMed $=251$, WOS $=942$, Cochrane $=7$ ). Six studies [10-15] containing 933 cases and 1,381 controls fulfilled the predefined inclusion criteria and were included in the final analysis. The literature selection process was shown in Figure 1. And the characteristics of included study were shown in the Table 1. All the subjects in the included studies were of Caucasian population. Among the six studies, there were three anterior cruciate ligament (ACL) injuries studies, one Achilles tendon injuries study, one Tennis elbow study and one shoulder dislocations and cruciate ligament (CL) injuries study. All the ACL injuries or CL injuries were surgically diagnosed and the shoulder dislocations were radiologically confirmed. Tennis elbow injuries were diagnosed using clinical criteria while the Achilles tendon injuries including the diagnoses of chronic Achilles tendinopathy and the partial or complete ruptures of the Achilles tendon. All the participants in the control groups were healthy participants without any history of ligament or tendon injuries. The genotyping distribution was in agreement with HWE in all studies.

\section{Association between COL1A1 rs1800012 polymorphism and sports-related tendon and ligament injuries susceptibility}

In allele model, random-effects model was used due to presence of heterogeneity. No significant heterogeneity was identified by I-squared statistic in any of the rest genetic models and thus fixed-effects model was used. Overall, significant association was identified in homozygote model (TT versus $\mathrm{GG}$ : $\mathrm{OR}=0.17,95 \% \mathrm{CI}$ $0.08-0.35, P_{\mathrm{H}}=0.00$ Figure 2 ) and recessive model (TT versus $\mathrm{GT} / \mathrm{GG}$ : $\mathrm{OR}=0.21,95 \% \mathrm{CI} 0.10-0.44, P_{\mathrm{H}}=0.00$ Figure 3). No significant association was found in allele model (T versus $\mathrm{G}$ : $\mathrm{OR}=0.89,95 \% \mathrm{CI} 0.75-1.05, P_{\mathrm{H}}=$ 0.17 ), heterozygote model (GT versus $\mathrm{GG}$ : $\mathrm{OR}=1.13$, 95\%CI 0.93-1.38, $P_{\mathrm{H}}=0.23$ ), and dominant model (TT/ GT versus $\mathrm{GG}$ : OR $\left.=1.00,95 \% \mathrm{CI} 0.83-1.22, P_{\mathrm{H}}=0.97\right)$. (see Table 2)

Next, subgroup analysis was conducted according to different diagnoses. The association between COL1A1 rs1800012 polymorphism and the risk of ACL injuries was analyzed in three independent studies. In ACL injuries, no significant statistical heterogeneity was identified in any genetic model so that fixed-effects model was used. Significant association was found in homozygote model (TT versus $\mathrm{GG}$ : $\mathrm{OR}=0.23,95 \% \mathrm{CI} 0.07-0.79, P_{\mathrm{H}}=0.02$ Figure 4), and recessive model (TT versus $\mathrm{GT} / \mathrm{GG}$ : OR = $0.21,95 \% \mathrm{CI} 0.06-0.73, P_{\mathrm{H}}=0.01$ Figure 5). No significant association was found in allele model (T versus $\mathrm{G}$ : OR= 
1200 of records identified through database searching (PubMed $=251$, WOS $=942$, Cochrane $=7$ )

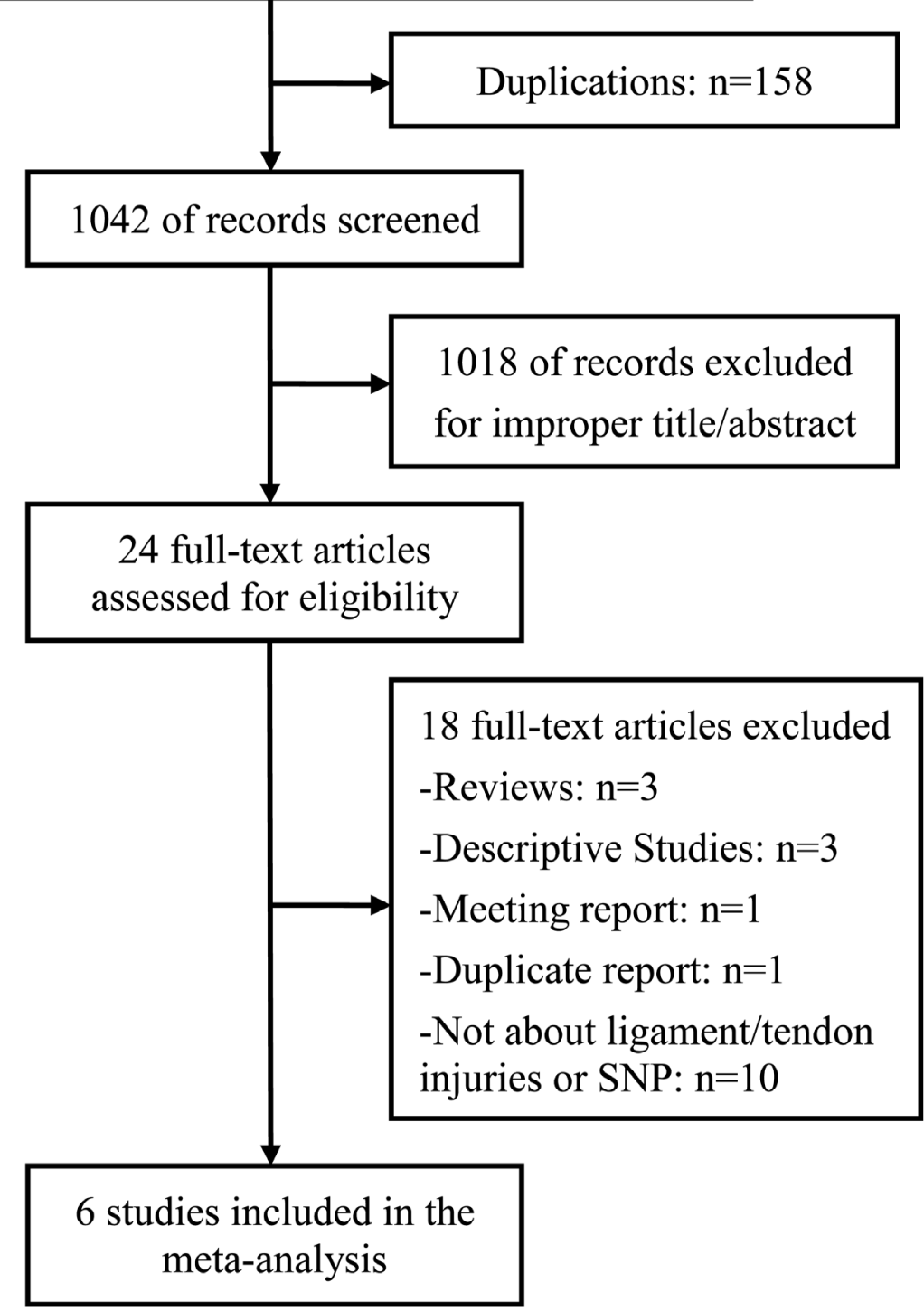

Figure 1: Flow diagram of studies identified, included, and excluded.

\begin{tabular}{|c|c|c|c|c|c|c|c|c|c|c|c|}
\hline Study or Subgroup & $\begin{array}{l}\text { Case } \\
\text { Events }\end{array}$ & Total & $\begin{array}{l}\text { Contr } \\
\text { Events }\end{array}$ & $\begin{array}{l}\text { ol } \\
\text { Total }\end{array}$ & Weight & $\begin{array}{l}\text { Odds Ratio } \\
\text { M-H, Fixed, } 95 \% \mathrm{Cl}\end{array}$ & Year & \multicolumn{4}{|c|}{$\begin{array}{c}\text { Odds Ratio } \\
\text { M-H, Fixed. } 95 \% \mathrm{Cl}\end{array}$} \\
\hline Khoschnau 2008 & 2 & 259 & 12 & 242 & $27.3 \%$ & $0.15[0.03,0.67]$ & 2008 & & & & \\
\hline Posthumus 2009a & 0 & 80 & 6 & 97 & $12.9 \%$ & $0.09[0.00,1.58]$ & $2009 a$ & & & & \\
\hline Posthumus 2009b & 2 & 93 & 6 & 95 & $12.9 \%$ & $0.33[0.06,1.66]$ & $2009 b$ & & & & \\
\hline Stepien-Slodkowska 2013 & 0 & 65 & 5 & 44 & $14.4 \%$ & $0.05[0.00,1.02]$ & 2013 & & & & \\
\hline Ficek 2013 & 2 & 92 & 6 & 47 & $17.2 \%$ & $0.15[0.03,0.78]$ & 2013 & & & & \\
\hline Erduran 2014 & 2 & 71 & 7 & 68 & $15.4 \%$ & $0.25[0.05,1.26]$ & 2014 & & & & \\
\hline Total $(95 \% \mathrm{Cl})$ & & 660 & & 593 & $100.0 \%$ & $0.17[0.08,0.35]$ & & & & & \\
\hline Total events & 8 & & 42 & & & & & & & & \\
\hline $\begin{array}{l}\text { Heterogeneity: } \mathrm{Chi}^{2}=1.69 \\
\text { Test for overall effect: } Z=\end{array}$ & $\begin{array}{l}f=5(P= \\
78(P<0 .\end{array}$ & $\begin{array}{c}0.89 \text { ); } \\
\text { D0001) }\end{array}$ & $1^{2}=0 \%$ & & & & & 0.001 & 0.1 & 10 & 1000 \\
\hline
\end{tabular}

Figure 2: Forest plot of homozygote model of COL1A1 rs1800012 for overall comparison (TT versus GG). 
$1.02,95 \%$ CI $\left.0.78-1.33, P_{\mathrm{H}}=0.90\right)$, heterozygote model (GT versus GG: $\mathrm{OR}=1.34,95 \% \mathrm{CI} 0.98-1.83, P_{\mathrm{H}}=0.07$ ), and dominant model (TT/GT versus GG: OR $=1.19$, $95 \%$ CI $0.87-1.61, P_{\mathrm{H}}=0.27$ ). (see Table 2)

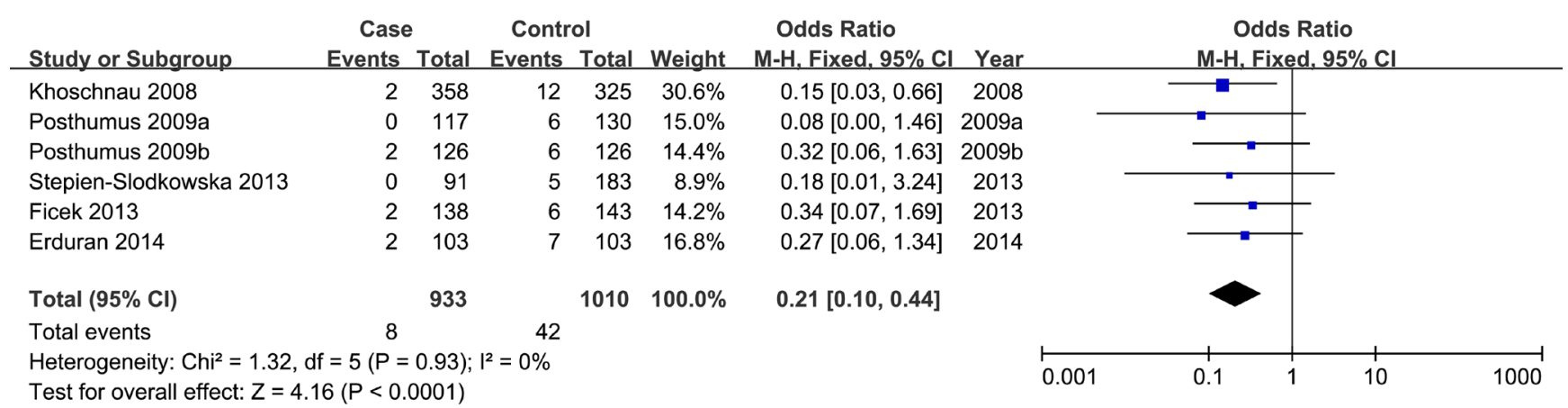

Figure 3: Forest plot of recessive model of COL1A1 rs1800012 for overall comparison (TT versus GT+GG).

\section{Sensitivity analysis}

Sensitivity analysis was performed to examine the influence set by the individual study on the pooled ORs

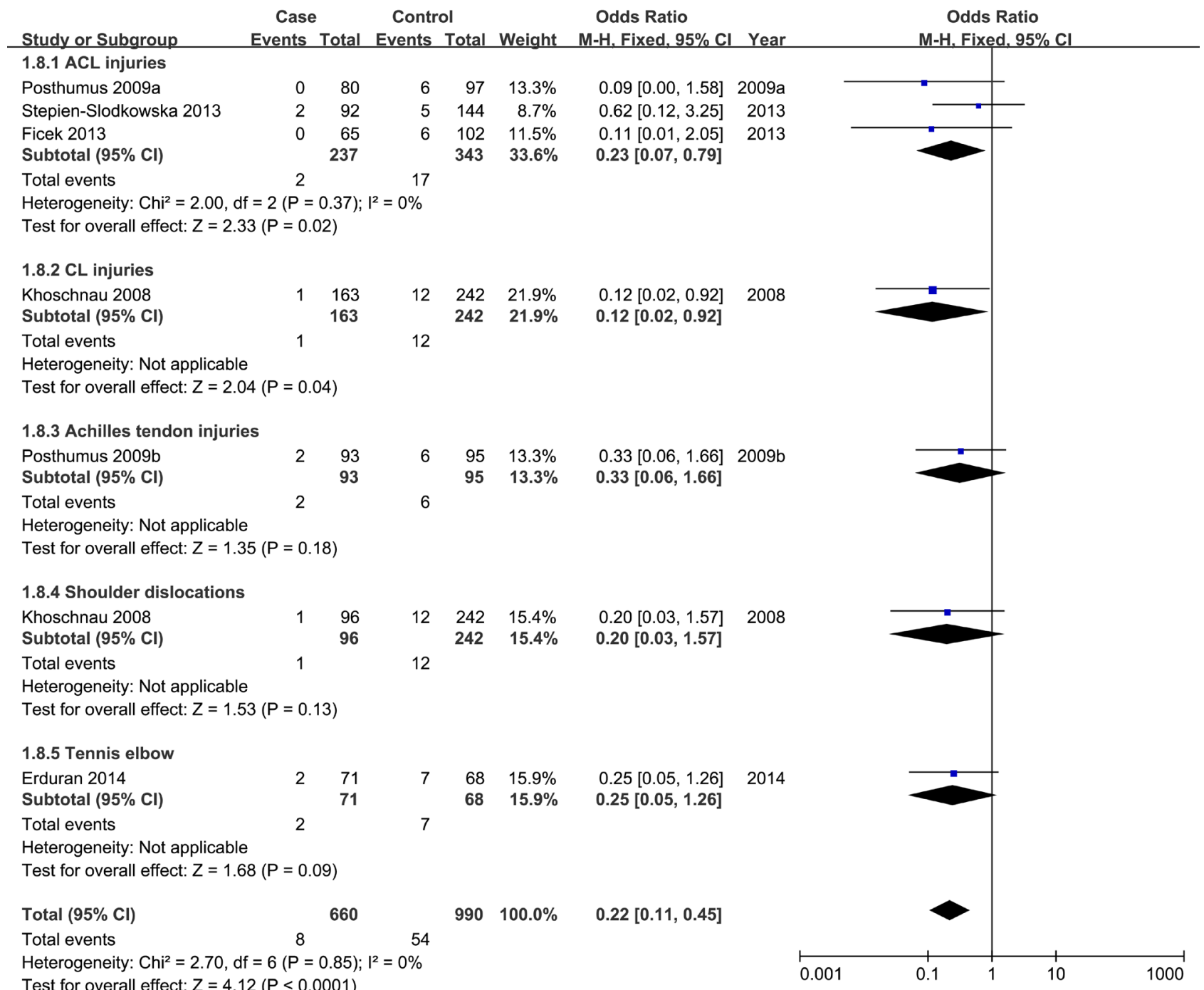

Figure 4: Forest plot of homozygote comparison of COL1A1 rs1800012 for subgroup analysis stratified by diagnosis (TT versus GG). 
for COL1A1 rs1800012 polymorphism by deleting one study each turn in every genetic model. [16] There was no change in the significance of any of the outcomes except for the allele model, in which the pooled estimate showed statistical difference after excluding the study of StepienSlodkowska [15] (T versus G: OR $=0.81,95 \%$ CI 0.67 $\left.0.98, P_{\mathrm{H}}=0.03\right)$.

\section{DISCUSSION}

This meta-analysis of six eligible case-control studies including 933 cases comparing 1381 healthy controls showed that rare TT genotype was likely a protective factor for sports-related tendon and ligament injuries, as the odds ratio was 0.17 in the homozygote model and 0.21 in the recessive model respectively.
In subgroup analysis, similar results were found when the analysis was limited to ACL injuries. However, this finding should be interpreted with caution for limited sample heterogeneity.

Type 1 collagen, representing up to $80 \%$ of the dry weight of tendon and ligament tissue [17], is composed of two chains: $\alpha 1$ and $\alpha 2$, at a ratio of $2: 1$. The COL1A 1 gene encodes for the $\alpha 1$ chain and a polymorphism of this gene may affect the gene transcription, leading to a change in the $\alpha 1 / \alpha 2$ ratio, then generating a mature collagen protein with an altered structure. [5, 18] Among the various SNPs, rs1800012 is the most studied one and has been associated with connective tissue disorders such as osteogenesis imperfecta [19], osteoarthritis [20], and soft tissue injuries in a combined analysis [21]. Previous studies showing a significant genotypic association of COL1A1 rs1800012 polymorphism TT genotype with

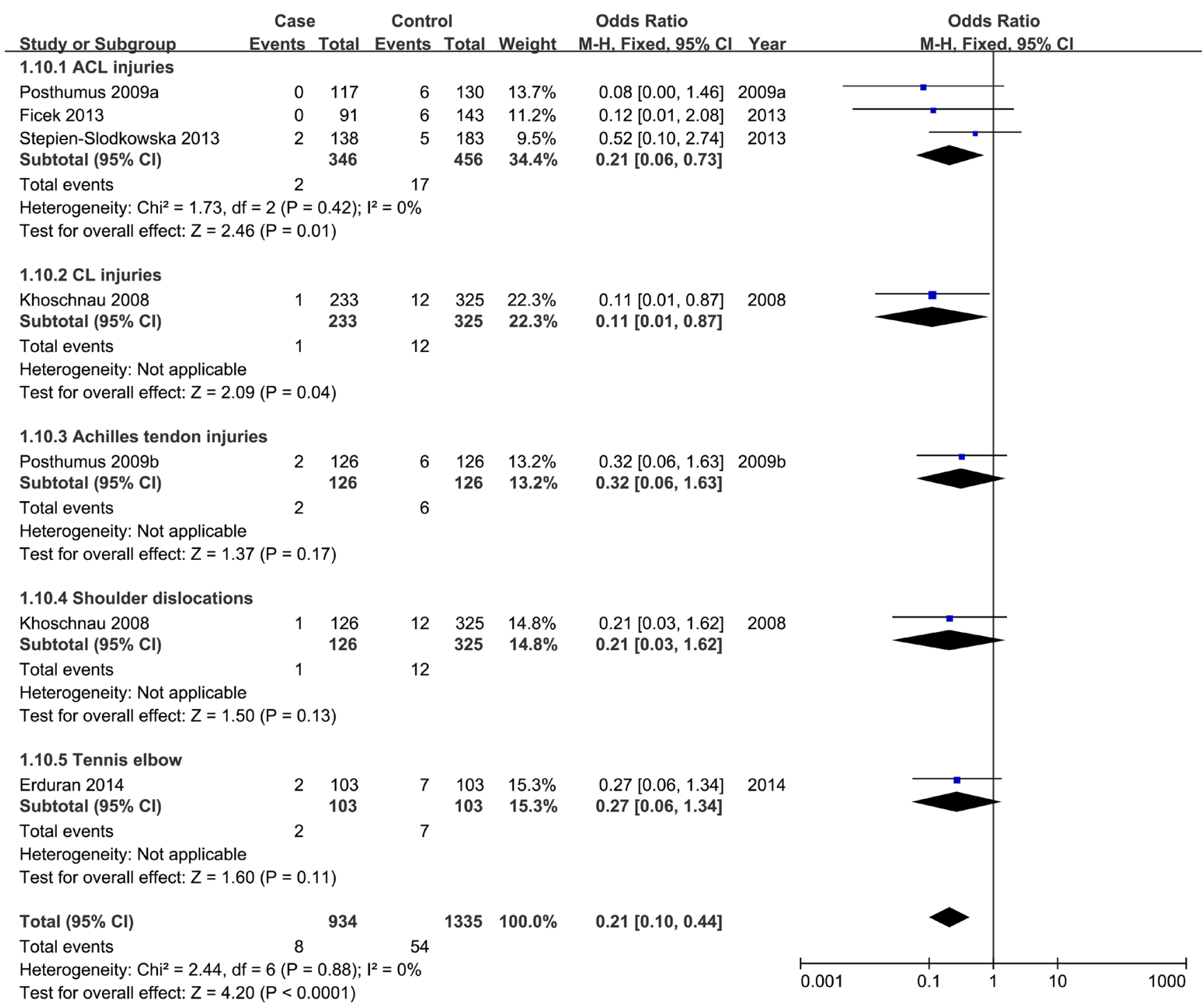

Figure 5: Forest plot of recessive comparison of COL1A1 rs1800012 for subgroup analysis stratified by diagnosis (TT versus $\mathbf{G T}+\mathbf{G G})$. 
tendon and ligament injuries can be found in a Sweden population [12] and a Poland population [11], although this finding could not be replicated by another Poland population study [15]. No significant association of rs1800012 SNP was noted in two South Africa works $[13,14]$ and a Turkey examine $[10]$, as well as a noneCaucasian study [22]. By the way, there is a second COL1A1 polymorphism (COL1A1 1997G/T, rs1107946) that has been studied with the incidence of ACL injuries, whereas no significant association was identified. [11, 23]

Our meta-analysis has several strengths. In the first place, this is the first meta-analysis focused on the association between COL1A1 polymorphism and the susceptibility to sports-related tendon and ligament injuries. Compared with the former review regarding ACL injury gene etiology [24], more COL1A1 studies were included and more systematic and specified meta-analysis was performed. Moreover, multiple strategies and strict criteria were used to evaluate the methodological quality of the studies, all the enrolled studies possessed high qualities and no study was calculated significant departure from Hardy-Weinberg equilibrium (HWE). The last but not the least, no significant heterogeneity was detected in any genetic models, thus our meta-analysis results enjoys high credibility.

The present meta-analysis has the following limitations that must be taken into account. Firstly, the number of included studies for COL1A1 rs1800012 polymorphism limited further analysis due to shortage of original studies. Secondly, the cases enrolled in this study are from different sports groups, some are skiers, some are soccer players, while some others were not mentioned. To our knowledge, sports-related tendon and ligament injuries have both intrinsic and extrinsic risk factors [25] , characters from different sports groups may lead an influence to the final results. Thirdly, in one of the enrolled studies [12], two different injuries cases were compared to the same control group, then the control number in the subgroup analysis was a little larger than it really is, resulting in the subgroup analysis results being treated with cautionary attention. What's more, all the including studies were Caucasian ethnicity, more studies basing on other ethnicities remained to be performed.

In conclusion, our results indicated that COL1A1 rs1800012 polymorphism may be associated with the reduced risk of sports-related tendon or ligament injuries, especially in ACL injuries, and that rare TT may played as a protective role. Nevertheless, despite our rigorous methodology, the inherent limitations of included studies and insufficient data prevent us from definitive confirming the association of sports-related tendon or ligament injuries and rs 1800012 in COL1A1. Future studies with large-volume and more ethnic groups are awaited to validate and update the findings of this analysis.

\section{METHODS AND MATERIALS}

\section{Identification of eligible studies}

A literature search was performed in Pubmed, Web Of Science and Cochrane Library databases on June 2, 2016, without restriction to regions, publication types, or languages. We used the following search terms in [Title/ Abstract]: [Collagen Type I Alpha I OR Collagen Type I Alpha1 OR Collagen Type1 Alpha 1 OR Collagen Type I $\alpha 1$ OR Collagen Type $1 \alpha 1$ OR Type 1 Collagen $\alpha 1$ OR Type I Collagen $\alpha 1$ OR Colla1 OR COL1A1 OR COLIA1] AND [muta* OR varia* OR polymorphi* OR SNP] AND [Wounds and injuries OR injur* OR trauma* OR sprain* OR strain* OR fracture* OR bone broke OR dislocation* OR tendinopathy OR luxation* OR contusion* OR tendon* OR muscle tear OR rupture*]. The reference lists of all retrieved studies, review articles, and conference abstracts were also manually searched for further relevant studies.

\section{Inclusion and exclusion criteria}

Virtually all common sports injuries occurred in the shoulder, elbow, knee or ankle joint. Sports injuries which will be covered in this meta-analysis include the rotator cuff tendon injuries in the shoulder (rotator cuff injuries), tendon injuries in the elbow (tennis elbow), the cruciate ligament injures in the knee (cruciate ligament injuries), and Achilles tendon injuries in the ankle (Achilles tendon injuries). Studies in this meta-analysis must also meet the following inclusion criteria: (1) evaluation of the association between COL1A1 polymorphisms and sports injuries; (2) case-control study; (3) studies focusing on human being; (4) detailed genotype data could be acquired to calculate the odds ratios (ORs) and 95\% confidence intervals (CIs); Exclusion criteria: (1) duplication of previous publications; (2) comment, review and editorial; (3) family-based studies of pedigrees; (4) study with no detailed genotype data. When there were multiple publications from the same population, the most recent or complete study was included. Eligible studies was achieved by two contributing authors independently in accordance with the inclusion and exclusion criteria by screening the titles, abstracts and full-text. Any disagreement was resolved by discussions.

\section{Data extraction}

Data from the included studies were extracted and summarized independently by two of the authors ( $\mathrm{Li}$ and Chen). Any disagreement was resolved by the adjudicating senior authors (Liu and Wang). The contents listed below 
were collected: name of first author, year of publication, the characteristics of cases and controls, country of origin, the detective sample, ethnicity, genotyping methods, the criteria of injury, Hardy-Weinberg equilibrium, number of cases and controls, genotype frequency in cases and controls.

\section{Methodological quality assessment}

Studies were rated for the level of evidence provided according to the Newcastle-Ottawa scale [24, 26], which consists of three factors: study selection (4 items; 1 star can be awarded for each item), comparability of cases ( 2 stars can be awarded), and exposure ( 2 items; 1 star can be awarded for each item). A score of 0-8 (allocated as stars) was allocated to each study and a high score means excellent quality of the study. Two investigators scored the studies independently and solved disagreement through discussion.

\section{Statistics analysis}

We conducted our meta-analysis following preferred reporting items for systematic reviews and meta-analyses (PRISMA) statement [27]. We evaluated Hardy-Weinberg equilibrium (HWE) for each study, and $P<0.05$ was considered a significant departure from HWE. OR and 95\% CIs were calculated to evaluate the strength of the association between COL1A1 SNP and susceptibility to sports injuries. Pooled ORs were performed for allelic comparison ( $\mathrm{T}$ versus $\mathrm{G}$ ), heterozygote model (GT versus GG), homozygote model (TT versus GG), dominant model (TT + GT versus GG ), recessive model (TT versus GT + GG), respectively. A statistical Z-test was used and P value less than 0.05 was taken to indicate statistical significance. Statistical heterogeneity was evaluated using Cochran Q tests and the $\mathrm{I}^{2}$ statistic (greater than $50 \%$ as evidence of significant inconsistency) [28]. The random-effects model was used if there was heterogeneity between studies; otherwise, the fixed-effects model was used. Subgroup analyses were carried out on stratification of different injury types. Sensitivity analyses were performed to evaluate the effect of each study on the combined ORs. All statistical analyses were performed using Review Manager 5.3 (Cochrane Collaboration, Oxford, UK).

\section{CONFLICTS OF INTEREST}

The authors declare that they have no conflicts of interest.

\section{REFERENCES}

1. Goodlin GT, Roos AK, Roos TR, Hawkins C, Beache S, Baur S and Kim SK. Applying personal genetic data to injury risk assessment in athletes. PloS one. 2014; 10:e0122676.

2. Jarvinen TA, Kannus P, Maffulli N and Khan KM. Achilles tendon disorders: etiology and epidemiology. Foot and ankle clinics. 2005; 10:255-266.

3. Hoffmann A and Gross G. Tendon and ligament engineering in the adult organism: mesenchymal stem cells and genetherapeutic approaches. International orthopaedics. 2007; 31:791-797.

4. Collins M, Raleigh SM. Genetic risk factors for musculoskeletal soft tissue injuries. Med Sport Sci. 2009; 54:136-49.

5. Mann V, Hobson EE, Li B, Stewart TL, Grant SF, Robins SP, Aspden RM and Ralston SH. A COL1A1 Sp1 binding site polymorphism predisposes to osteoporotic fracture by affecting bone density and quality. The Journal of clinical investigation. 2001; 107:899-907.

6. Xie P, Liu B, Zhang L, Chen R, Yang B, Dong J and Rong L. Association of COL1A1 polymorphisms with osteoporosis: a meta-analysis of clinical studies. International journal of clinical and experimental medicine. 2015; 8:14764-14781.

7. Van Heyningen V and Yeyati PL. Mechanisms of nonMendelian inheritance in genetic disease. Human molecular genetics. 2004; 13 Spec No 2:R225-233.

8. Collins M. Genetic risk factors for soft-tissue injuries 101: a practical summary to help clinicians understand the role of genetics and 'personalised medicine'. British journal of sports medicine. 2010; 44:915-917.

9. Pitsiladis Y, Wang G, Wolfarth B, Scott R, Fuku N, Mikami E, He Z, Fiuza-Luces C, Eynon N and Lucia A. Genomics of elite sporting performance: what little we know and necessary advances. British journal of sports medicine. 2013; 47:550-555.

10. Erduran M, Altinisik J, Meric G, Ates O, Ulusal AE and Akseki D. Is Sp1 binding site polymorphism within COL1A1 gene associated with tennis elbow? Gene. 2014; 537:308-311.

11. Ficek K, Cieszczyk P, Kaczmarczyk M, MaciejewskaKarlowska A, Sawczuk M, Cholewinski J, Leonska-Duniec A, Stepien-Slodkowska M, Zarebska A, Stepto NK, Bishop DJ and Eynon N. Gene variants within the COL1A1 gene are associated with reduced anterior cruciate ligament injury in professional soccer players. Journal of science and medicine in sport / Sports Medicine Australia. 2013; 16:396-400.

12. Khoschnau S, Melhus H, Jacobson A, Rahme H, Bengtsson H, Ribom E, Grundberg E, Mallmin H and Michaelsson $\mathrm{K}$. Type I collagen alpha1 Sp1 polymorphism and the risk of cruciate ligament ruptures or shoulder dislocations. The American journal of sports medicine. 2008; 36:2432-2436.

13. Posthumus M, September AV, Keegan M, O'Cuinneagain D, Van der Merwe W, Schwellnus MP and Collins M. Genetic risk factors for anterior cruciate ligament ruptures: 
COL1A1 gene variant. British journal of sports medicine. 2009; 43:352-356.

14. Posthumus M, September AV, Schwellnus MP and Collins M. Investigation of the Sp1-binding site polymorphism within the COL1A1 gene in participants with Achilles tendon injuries and controls. Journal of science and medicine in sport / Sports Medicine Australia. 2009; 12:184-189.

15. Stepien-Slodkowska M, Ficek K, Eider J, Leonska-Duniec A, Maciejewska-Karlowska A, Sawczuk M, Zarebska A, Jastrzebski Z, Grenda A, Kotarska K and Cieszczyk P. The $+1245 \mathrm{~g} / \mathrm{t}$ polymorphisms in the collagen type I alpha 1 (colla1) gene in polish skiers with anterior cruciate ligament injury. Biology of sport. 2013; 30:57-60.

16. Li K, Tie H, Hu N, Chen H, Yin X, Peng C, Wan J and Huang W. Association of two polymorphisms rs2910164 in miRNA-146a and rs3746444 in miRNA-499 with rheumatoid arthritis: a meta-analysis. Human immunology. 2014; 75:602-608.

17. Frank CB. Ligament structure, physiology and function. Journal of musculoskeletal \& neuronal interactions. 2004; 4:199-201.

18. Villegas-Martinez I, de-Miguel-Elizaga I, Carrasco-Torres R, Marras C, Canteras-Jordana M, Yedra-Guzman MJ, Martinez-Villanueva M, Tortosa-Conesa D and MartinFernandez J. The COL1A1 SP1 polymorphism is associated with lower bone mineral density in patients treated with valproic acid. Pharmacogenet Genomics. 2016; 26:126-132.

19. Marini JC and Blissett AR. New genes in bone development: what's new in osteogenesis imperfecta. The Journal of clinical endocrinology and metabolism. 2013; 98:3095-3103.

20. Loughlin J, Sinsheimer JS, Mustafa Z, Carr AJ, Clipsham K, Bloomfield VA, Chitnavis J, Bailey A, Sykes B and Chapman K. Association analysis of the vitamin D receptor gene, the type I collagen gene COL1A1, and the estrogen receptor gene in idiopathic osteoarthritis. The Journal of rheumatology. 2000; 27:779-784.
21. Collins M, Posthumus $M$ and Schwellnus MP. The COL1A1 gene and acute soft tissue ruptures. British journal of sports medicine. 2010; 44:1063-1064.

22. John R, Dhillon M, Prabhakar S and Anand A. Association of Gene Polymorphisms in COL1A1 and COL12A1 with ACL Tears - A Study in the Indian Population. International Journal of Conference Proceedings 2015.

23. Stepien-Slodkowska M, Ficek K, Zietek P, Kaczmarczyk M, Lubkowska W, Szark-Eckardt M and Cieszczyk P. Whether the Combination of COL1A1 Gene Polymorphisms may be a Marker of the Risk of Injury? Journal of sport rehabilitation. 2016.

24. John R, Dhillon MS, Sharma S, Prabhakar S and Bhandari M. Is There a Genetic Predisposition to Anterior Cruciate Ligament Tear? A Systematic Review. The American journal of sports medicine. 2016.

25. Shultz SJ, Schmitz RJ, Benjaminse A, Collins M, Ford $\mathrm{K}$ and Kulas AS. ACL Research Retreat VII: An Update on Anterior Cruciate Ligament Injury Risk Factor Identification, Screening, and Prevention. J Athl Train. 2015; 50:1076-1093.

26. GA Wells, B Shea, D O'Connell, J Peterson, V Welch, M Losos and P Tugwell. The Newcastle-Ottawa Scale (NOS) for assessing the quality of nonrandomised studies in metaanalyses.

27. Moher D, Liberati A, Tetzlaff J, Altman DG and Group P. Preferred reporting items for systematic reviews and meta-analyses: the PRISMA statement. Annals of internal medicine. 2009; 151:264-269, W264.

28. Higgins JP and Thompson SG. Quantifying heterogeneity in a meta-analysis. Stat Med. 2002; 21:1539-1558. 